\title{
Meating Conflict: Toward a Model of Ambivalence-Motivated Meat Reduction.
}

Shiva Pauer ${ }^{1}$, https://orcid.org/0000-0001-5965-8040

Bastiaan T. Rutjens ${ }^{1}$, https://orcid.org/0000-0003-3163-4156

Matthew B. Ruby ${ }^{2}$, https://orcid.org/0000-0002-9562-6510

Grischa Perino ${ }^{3}$, https://orcid.org/0000-0001-6519-1029

Frenk van Harreveld ${ }^{1,4}$, https://orcid.org/0000-0003-3717-2773

${ }^{1}$ Department of Social Psychology, University of Amsterdam, The Netherlands

${ }^{2}$ School of Psychology and Public Health, La Trobe University, Australia

${ }^{3}$ Faculty of Business, Economics and Social Sciences, University of Hamburg, Germany

${ }^{4}$ National Institute for Public Health and the Environment (RIVM), The Netherlands

Corresponding author:

Shiva Pauer

University of Amsterdam, Department of Social Psychology

Nieuwe Achtergracht 129-B, Amsterdam, The Netherlands

Email: s.pauer@uva.nl 


\begin{abstract}
An increasing number of people is concerned about eating meat despite enjoying doing so. In the present research, we examined whether the desire to resolve this ambivalence about eating meat leads to a reduction in meat consumption. Our model of ambivalence-motivated meat reduction proposes that the pervasive nature of evaluative conflict motivates meat avoidance, and we highlight two potential mechanisms involved: the anticipation of ambivalence reduction through behavioral change, and information seeking aimed at facilitating behavioral change. Study 1 drew on a 6-day food diary with 7,485 observations in a quota sample to investigate the predictors of meat-related ambivalence and demonstrate its correlation with meat reduction. Two experiments showed that ambivalence-induced discomfort motivated participants to eat less meat when they introspected on their preexisting incongruent evaluations (Study 2 and 3), which was mediated by the aforementioned mechanisms involved (Study 3; preregistered). The studies utilized diverse samples from Germany, England, and the US (total $N=1,192)$ and indicate that behavioral change is an important coping strategy to resolve ambivalent discomfort in the context of meat consumption. Our model of ambivalence-motivated meat reduction contributes to theorizing on the consequences of ambivalence and the psychology of (not) eating meat.
\end{abstract}

Keywords: ambivalence, behavioral change, food choice, information-seeking, meat 


\section{Introduction}

Meat consumption is a cherished behavior around the world (OECD \& FAO, 2020). Many people value the nutritional density, joy, and sociability associated with meat (Arbit et al., 2017; Ruby et al., 2016). At the same time, an increasing number of them are concerned about the detrimental effects of meat consumption on human health, farmed animals, and the environment (de Boer et al., 2013; Ruby et al., 2016; Siegrist et al., 2015). Indeed, the average global meat intake substantially exceeds the recommended maximum intake, which has been attributed to about 155,000 human deaths in 2017 due to cardiovascular disease, diabetes, and cancer (Afshin et al., 2019). Additional meat-related health implications include foodborne infections and pathogens as well as antibiotic resistance (Godfray et al., 2018). Moreover, cutting down on animal products is one of the most effective individual climate actions (Wynes \& Nicholas, 2017), and surveys in the (German) general public have also shown that the prevailing animal production systems are judged as morally impermissible (Federal Ministry of Food and Agriculture, 2016; Hartmann \& Siegrist, 2020). These contradictory evaluations of meat can give rise to ambivalence about eating it (Berndsen \& van der Pligt, 2004; Buttlar \& Walther, 2018; Rozin \& Ruby, 2020).

Berndsen and van der Pligt (2004) indicated that ambivalence about meat could be widespread in students and negatively correlated with meat consumption above and beyond the effects of meat-related attitudes, beliefs, and perceived social norms. Although there is ample converging evidence for such a correlation of ambivalence with behavioral change (e.g., Armitage \& Arden, 2007; Emmons \& King, 1988; Hofmann et al., 2012), previous studies have not investigated the causal direction and underlying processes.

In the present article, we shed light on how meat-related evaluative conflict can lead to the reduction of meat intake. We draw on previous research on meat consumption and attitudinal ambivalence to argue that inconsistent evaluations of meat can cause a pervasive 
meta-cognitive awareness of ambivalence. Consequently, the expectation of encountering aversive feelings of ambivalence should motivate information processing in a way conducive to meat reduction. As such, we expect ambivalence to cause a motivation to eat less meat due to the need to reduce experienced conflict.

\section{Ambivalence-Motivated Meat Reduction}

The meta-cognitive awareness of conflict about an attitude object (hereinafter: felt ambivalence) is an aversive state that can arise from the coexistence of strong but incongruent evaluations within the attitude (hereinafter: potential ambivalence; e.g., Priester \& Petty, 1996; van Harreveld, van der Pligt, et al., 2009). Measures of objective and subjective ambivalence often correlate modestly (Armitage \& Arden, 2002), reflecting the notion that ambivalence can either be salient or remain in a dormant (and exclusively structural) state. Someone could hold equally strong positive and negative evaluations of an attitude object - e.g., believing that meat has both health benefits and risks - but this potential ambivalence might elicit feelings of conflict only in situations that make the incongruence salient, such as in deciding how much meat to purchase when grocery shopping. ${ }^{1}$

Previous research has highlighted two distinct associations of ambivalence with behavior. First, ambivalence has been associated with attitude strength, with ambivalent attitudes being weaker than univalent attitudes. Specifically, potential ambivalence has been found to moderate the attitude-behavior relationship, such that attitudes have lower predictive value at high ambivalence in the context of meat- and plant-based food choices (Armitage \& Conner, 2000; Conner et al., 2002, 2003; Sparks et al., 2001; but see Ullrich et al., 2008). Moreover, felt ambivalence has been found to have moderate to large correlations with

\footnotetext{
${ }^{1}$ In contrast to a conflict within the attitude (i.e., ambivalence), research on cognitive dissonance (Festinger, 1957) focuses on situational conflicts between behavior and cognition (see Dalege et al., 2019). Bastian et al. (2012), for example, examined dissonance reduction processes in participants who expected to sample meat after reading critical information related to its animal origin. We elaborate on this distinction below. Similarly, the present research focusses on ambivalence about meat but not conflict from choosing between multiple options (e.g., Tversky \& Shafir, 1992), such as between meat and meat-free options.
} 
intentions to eat less meat and self-reported meat reduction (Amiot et al., 2020, Study 6; Armitage \& Arden, 2007; Berndsen \& van der Pligt, 2004).

A second reason why ambivalence could motivate behavioral change lies in the stability and aversiveness of ambivalent attitudes. Ambivalence toward food and personal goals can be chronic, in many cases lasting longer than a year (Emmons \& King, 1988; Keller \& Siegrist, 2015), even though ambivalence has detrimental effects on affective states and well-being (Moberly \& Dickson, 2018; Proulx et al., 2012; van Harreveld, Rutjens, et al., 2009). In line with this assertion, recent research demonstrated that felt ambivalence can come to light when judging pictures of meat (Buttlar \& Walther, 2018; Norris et al., 2019), and such visual stimuli are ubiquitous, for instance in supermarkets. Another elicitor of felt ambivalence is food choice (Becker et al., 2019), because the experience of ambivalence particularly arises when a decision has to be made (Itzchakov \& van Harreveld, 2018; van Harreveld, Rutjens, et al., 2009). Chronic ambivalence about meat could therefore involve the aversive recurrence of experiences of ambivalence in daily life situations.

The pervasiveness of ambivalence toward meat indicates that it can be difficult to restore a univalent attitude toward it. Specifically, alleviating ambivalent discomfort through coping strategies that may frequently be involved in maintaining meat consumption after attitude-behavior conflicts (i.e., meat-related cognitive dissonance; Bastian \& Loughnan, 2016; Loughnan et al., 2014) would afford only temporary relief to individuals who are chronically ambivalent. For example, situational underreporting of one's meat consumption as a response to experiences of meat-related threat (De Groeve \& Rosenfeld, 2021; Rothgerber, 2018) will not resolve potential ambivalence in the long term or prevent felt ambivalence from chronically recurring.

In the absence of effective mechanisms to regain a stable univalent attitude and avert experiences of ambivalence, one way to nonetheless reduce the aversive recurrence of felt 
ambivalence could be avoiding the attitude object, i.e. avoidance of meat. According to pervasive models of ambivalence (van Harreveld et al., 2015; van Harreveld, van der Pligt, et al., 2009), avoiding the elicitors of felt ambivalence could be a coping strategy that facilitates the regulation of ambivalence. In line with this assertion, research on choice conflict showed that people will avoid decisions in conflicted choice contexts more often than in unconflicted contexts (Anderson, 2003; Luce et al., 1997; Tversky \& Shafir, 1992). A similar avoidance mechanism might arise from ambivalence toward an attitude object. Specifically, the anticipation of ambivalence reduction (Clark et al., 2008; Perugini \& Bagozzi, 2001) could drive the avoidance of stimuli and situations that elicit felt ambivalence, with the aim to alleviate ambivalence-induced negative affect (van Harreveld et al., 2015). The avoidance of meat consumption may thus be perceived as an effective means to reduce the aversive recurrence of felt ambivalence.

Above, we argued that the pervasive nature of ambivalence motivates the avoidance of meat consumption through an anticipated reduction of ambivalence. Anticipated ambivalence reduction could also motivate people to seek information in order to facilitate successful ambivalence reduction through behavioral change. There is ample evidence that ambivalence can impact on information seeking (e.g., Jonas et al., 1997; Nordgren et al., 2006; Rothman et al., 2017), which has been conceptualized to be driven by the desire to resolve ambivalence and regain a more univalent attitude (van Harreveld et al., 2015). Clark et al. (2008), for instance, showed that ambivalence led to effortful information processing only if participants believed the information could reduce felt ambivalence. In particular, novel information is arguably instrumental in coping with barriers to eating less meat (Lea et al., 2006; Ruby, 2012), such as lack of cooking skills (Hartmann et al., 2013). Anticipated ambivalence resolution through meat reduction may therefore motivate seeking out information that facilitates plant-based food choices. 


\section{The Present Research}

In the current research, we aim to test a new model of ambivalence-motivated meat reduction (see Figure 1). The meta-cognitive awareness of evaluative conflict about eating meat (i.e., felt ambivalence) can primarily arise from strong but incongruent evaluations of meat (i.e., potential ambivalence). Chronically felt ambivalence should drive meat avoidance due to the desire to avert the negative affect of felt ambivalence. Specifically, we propose that the anticipation of ambivalence resolution through meat avoidance motivates behavioral change. This anticipation may increase information seeking to facilitate meat avoidance. Meat ambivalence should also directly motivate information seeking to reduce the ambivalence and gain confidence.

\section{Figure 1}

The model of ambivalence-motivated meat reduction investigated in studies 1 to 3 .

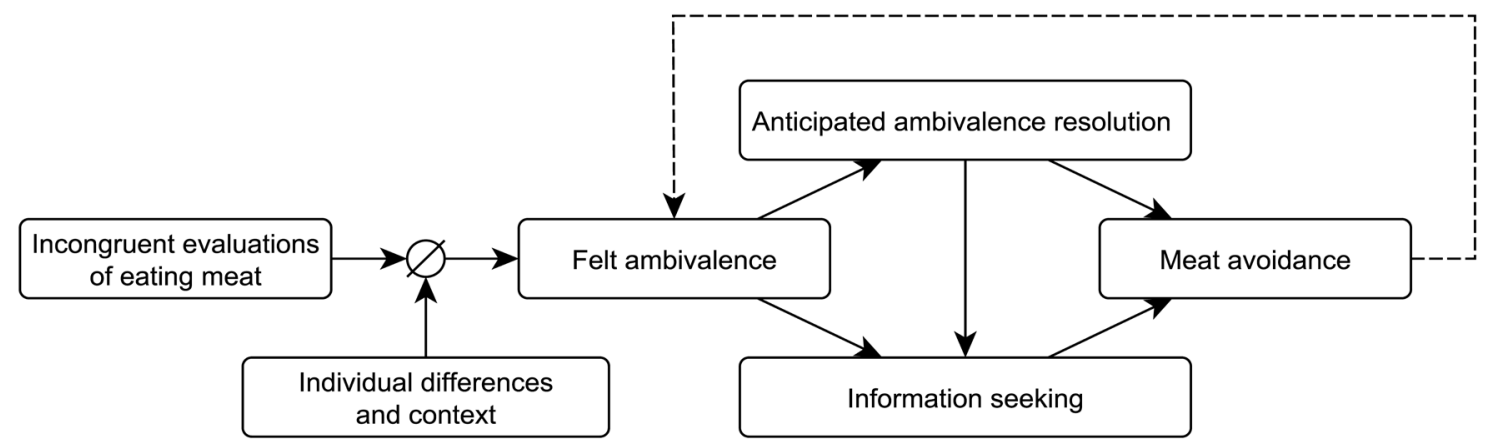

Numerous cultural, social, situational, and demographic variables could potentially affect whether felt ambivalence toward meat consumption arises in the first place. The simultaneous accessibility of incongruent evaluations can make felt ambivalence about eating meat salient (Berrios et al., 2015a; Newby-Clark et al., 2002; van Harreveld et al., 2014), for example, when individuals introspect or in food choice contexts (e.g., Buttlar \& Walther, $2018,2019,2022)$. Consequentially, cultural differences in the frequency of meat 
consumption might influence the frequency with which meat-related ambivalence is experienced. The typically moderate association of incongruent evaluations with felt ambivalence (see van Harreveld et al., 2015) could also be diminished by social influence (see Priester \& Petty, 2001; Toribio-Flórez et al., 2020) as well as coping strategies that aim to maintain meat consumption despite conflict (Bastian \& Loughnan, 2016; Loughnan et al., 2010; McGregor et al., 2019). Therefore, individual differences in meat-related moral disengagement (Graça et al., 2016; Onwezen \& van der Weele, 2016) as well as gender and age differences in coping strategies (Eschenbeck et al., 2007; Hampel \& Petermann, 2005) could influence the elicitation of felt ambivalence. The present research focuses especially on sociodemographic variables because previous research has often relied entirely on student samples.

A total of 3 studies investigated the proposed model (see Figure 1). Study 1 aimed to assess the prevalence of ambivalence toward eating meat and its sociodemographic predictors in the general public, as well as moderators of the association of potential with felt ambivalence. Moreover, we tested whether felt ambivalence correlates with a robust measure of meat reduction above and beyond perceived behavioral control over eating less meat. Such a role of felt ambivalence would provide initial support for the assumption that desire to alleviate ambivalent discomfort can motivate meat reduction.

We also investigated the causal direction of the consequences of ambivalence on meat consumption and further isolated the role of felt ambivalence in Study 2 and 3. To this end, we made meat-related ambivalence experimentally salient by asking participants to introspect on their incongruent evaluations of eating meat. Study 3 replicated Study 2 while directly assessing the potential pathways of how the elicitation of felt ambivalence could motivate 
meat reduction through increased anticipated ambivalence reduction and effortful information processing. $^{2}$

The studies reported in this article were approved by the Ethics Review Boards of the Department for Social Psychology, University of Amsterdam (2020-SP-12431, 2020-SP12489), and the WiSo Laboratories, University of Hamburg. All participants gave their informed consent for inclusion before they participated in the study. The hypotheses and analytic plans were specified before the data were collected if not stated otherwise. We report all data exclusions, experimental manipulations, measures, and sampling procedures.

\section{Study 1}

Study 1 aimed to examine the prevalence of meat ambivalence, its association with meat consumption, and the roles of sociodemographic variables in the proposed model of ambivalence-motivated meat reduction. To this end, we employed a 6-day food diary with non-deceptive obfuscation in a quota sample to roughly represent the German population of adults. We sought to distinguish the effects of strong but incongruent evaluations of eating meat (i.e., potential ambivalence) and meta-cognitive awareness of evaluative conflict (i.e., felt ambivalence) in the association of ambivalence with meat reduction. We expected that the aversiveness of felt ambivalence (King \& Emmons, 1990; van Harreveld, Rutjens, et al., 2009) and its motivational consequences (van Harreveld et al., 2015; van Harreveld, van der Pligt, et al., 2009) would be the primary drivers of meat avoidance, with the aim to avert the recurrence of the discomfort of felt ambivalence. However, instead of felt ambivalence motivating meat reduction, the barriers to eating less meat (see Ruby, 2012) could elicit felt ambivalence in people who attempt to eat less meat. We therefore controlled for perceived behavioral control over meat consumption.

\footnotetext{
${ }^{2}$ In addition, an Ancillary Study (see Supporting Information) explored the evaluative components that constitute meat ambivalence via a content analysis of the qualitative data from the introspective experimental manipulation employed in Study 2 and 3.
} 


\section{Method}

\section{Procedure}

An initial sample of 1,695 participants was drawn from the online panel of Kantar, a recruitment company. A screening survey assessed their demographic characteristics and diets (e.g., gluten-free, vegetarian, halal, alcohol-free). We invited only people who indicated that they eat meat and were willing to take all parts of the diary study. The company balanced the demographics according to the German population statistics. On Sunday, $25^{\text {th }}$ of November 2018, 882 participants started the first 3 days of the digital diary reports. Subsequently, participants were randomly assigned to read one out of three 100 -word paragraphs (as interventions for meat reduction) or a control condition (about unrelated health issues of children). Before, participants read an article to distract from the topic of meat consumption (i.e., about everyday life contexts of meal intake). These articles were part of an unrelated study that will be published separately - they did not influence the present findings as shown by pre-post and between-group comparisons (see Supporting Information). The remaining 3 days of diary reports were administered starting on the subsequent Sunday. Afterwards, a final questionnaire assessed psychological variables.

\section{Participants}

A total of 555 participants who ate meat completed all parts of the study. This corresponds to $62.9 \%$ of the people who started the diary study. Participant characteristics were relatively representative of the German population of adults in terms of age, gender, education, and region, there were no significant differences between the initial and final sample (see Table 1), $d \mathrm{~s}<0.10, p \mathrm{~s}>.05$. Strict meat avoiders were not invited to the diary study as they could not further reduce their meat consumption. Participants who completed the study received $€ 22$. 


\section{Table 1}

Characteristics of the initial and final samples in Study 1.

\begin{tabular}{|c|c|c|c|}
\hline \multicolumn{2}{|c|}{ Variable } & Final sample & Initial sample \\
\hline \multicolumn{2}{|c|}{$M_{\text {age }}\left(S D_{\text {age }}\right)$} & $52.49(13.62)$ & $51.09(15.14)$ \\
\hline \multicolumn{2}{|c|}{ Education $^{\dagger}$} & $49 \%$ & $48 \%$ \\
\hline \multicolumn{2}{|l|}{ Female } & $48 \%$ & $50 \%$ \\
\hline \multirow[t]{4}{*}{ Region } & North & $5 \%$ & $6 \%$ \\
\hline & East & $13 \%$ & $13 \%$ \\
\hline & West & $51 \%$ & $51 \%$ \\
\hline & South & $30 \%$ & $32 \%$ \\
\hline \multicolumn{4}{|c|}{ Note ${ }^{\dagger}$ Education (dummy-coded) refers to the } \\
\hline \multicolumn{4}{|c|}{ percentage of people with at least a qualification for } \\
\hline
\end{tabular}

\section{Materials}

Meat Consumption Frequency. A 6-day food record (Willett, 2012) assessed meat consumption and other food choices, resulting in a total of 7,485 meal observations. We incorporated non-deceptive obfuscation to distract from the topic of meat consumption to reduce non-target effects such as demand effects (Zizzo, 2010) and selection bias (Haynes \& Robinson, 2019), which can inflate associations with psychosocial determinants (Brug et al., 1994). Specifically, participants selected not only meat intake but also various other meal ingredients on a list of 13 categories - e.g., meat, potatoes, fruit. A total of eight additional questions were assessed as distractors from food choice or for an unrelated study, such as activities and intake of fluids (see Supporting Information for the questionnaire). Participants were asked to report a minimum of two meals per day or more immediately after the meal. 
Meat consumption frequency was calculated as the proportion of meals that included meat relative to the total number of meals reported by an individual.

Felt Ambivalence. Meta-cognitive awareness of evaluative conflict toward eating meat was measured with one item adapted from the Felt Ambivalence Questionnaire (Priester \& Petty, 1996; Schneider et al., 2015): “To what degree do you experience conflicting thoughts and/or feelings regarding eating meat?". The 5-point response scale ranged from not at all to very much.

Potential Ambivalence, negativity, and positivity. Two split semantic differential scales (Kaplan, 1972) measured positive and negative associations to eating meat: "How positive[/negative] are your thoughts and/or feelings regarding meat consumption?" $(r=$ .71). The 5-point response scales ranged from not at all positive[/negative] to extremely positive[/negative]. We calculated Thompson et al. (1995)'s score for potential ambivalence from the intensity of the positive $(\mathrm{P})$ and negative $(\mathrm{N})$ associations and subtracted their congruences: $(\mathrm{P}+\mathrm{N}) / 2-|\mathrm{P}-\mathrm{N}|$. High scores indicate both strong and opposed associations.

Perceived Behavioral Control. One item measured the perceived behavioral control (Ajzen \& Madden, 1986) that someone may experience in eating meat: "I can control whether and how much meat I eat". The 5-point response scale ranged from completely agree to completely disagree.

Sociodemographics. Sociodemographic information was assessed in 15 questions (see Supporting Information), for example, number and age of children, employment and health status, and social context (i.e., the number of vegetarian and vegan friends and family members).

\section{Results \& Discussion}

All regression coefficients are in standardized format. CIs are based on 5,000 bootstrap samples in mediation analyses. 


\section{Prevalence and determinants of meat ambivalence}

A one-sample t-test revealed a significant prevalence of felt ambivalence (FA; compared to nil) with considerable variance between individuals, $M=2.39, S D=1.18, t(554)$ $=47.72, p<.001, d=2.03$. A total of $66.8 \%$ of participants indicated that they experienced at least some meat-related conflict. Exploratory analyses showed that FA significantly correlated with five sociodemographic variables out of 15 (see Table 2). After stepwise exclusions in multiple regression, only gender $(1-$ female, $0-$ male $), \beta=.17, p<.001$, and social context, $\beta=.24, p<.001$, remained significant predictors, $R^{2}=.08$. Controlling for meat consumption frequency, the effects of gender, $\beta=.15, p<.001$, and social context, $\beta=$ $.21, p<.001$, remained significant.

\section{Table 2}

Predictive correlates of felt ambivalence about meat consumption.

\begin{tabular}{lcc}
\hline Variable & $r$ & $p$ \\
\hline Gender & .16 & $<.001$ \\
Social context & .23 & $<.001$ \\
Student & .14 & .001 \\
Age & -.13 & .003 \\
Part-time employment & .10 & .013 \\
Potential ambivalence & .41 & $<.001$ \\
\hline
\end{tabular}

Note. $N=555$. For gender $(1-$ female, $0-$ male $)$ and age, $N=553$.

To our knowledge, this is the first data to investigate the prevalence of FA in the general public. While the prevalence of FA may be considerably lower than in student samples, the present findings support the assumption that it is a relatively widespread 
phenomenon (Bastian \& Loughnan, 2016; Rozin, 2007). The findings show that individuals who are female or have more vegans and vegetarians in their social circle report greater FA. Interestingly, the gender difference holds above the correlation of gender with meat consumption indicated in previous research (Graça et al., 2018; Rothgerber, 2013; Ruby \& Heine, 2011), indicating that gender could influence FA above and beyond an epiphenomenological association due to the association of FA with meat consumption. The effect of social context is in line with previous research on interpersonal predictors of ambivalence (Priester \& Petty, 2001; Toribio-Flórez et al., 2020) and highlights that sociability could be a crucial elicitor of meat ambivalence.

As predicted and in line with previous research (see van Harreveld, van der Pligt, et al., 2009), the association of potential ambivalence (PA) with FA was only moderate (see Table 2). We therefore investigated the roles of gender and social context in moderation analyses that indicated interaction effects of the two variables with PA on FA. The PA-FA association was more pronounced in males, $\beta=.49$, than females, $\beta=.27, p \mathrm{~s}<.001$, with a significant interaction of gender and PA, $\beta=-.22, p=.006$. There were significant gender differences in FA at low levels of PA, $\beta=.51, p<.001$, and mean PA, $\beta=.23, p=.003$, but not at high PA, $\beta=-.04, p=.72$. Likewise, social context and PA interacted, $\beta=-.17, p=$ .013 , such that the PA-FA association was more pronounced at low $\mathrm{SC}, \beta=.41$, and mean social context, $\beta=.36$, than at high social context, $\beta=.25, p \mathrm{~s}<.001$. Social context significantly predicted FA only at low levels of PA, $\beta=.53, p<.001$, and mean PA, $\beta=.32$, $p<.001$, but not at high PA, $\beta=.10, p=.18$. There were no significant interaction effects on FA by social context and gender or by social context, gender, and PA, $\beta \mathrm{s}<.05, p \mathrm{~s}>.58$.

The findings substantiate our model of ambivalence-motivated meat reduction (see Figure 1) by highlighting that there are individual differences in the extent to which PA predicts FA. The gap in the merely moderate PA-FA association seems to depend in parts on 
female gender and social context increasing the likelihood of experiencing FA in individuals who show relatively low levels of PA. Interestingly, gender and social context did not significantly impact on FA at high PA, which will be elaborated upon in the General Discussion.

\section{Ambivalence and meat consumption}

On average, $46.3 \%$ of the reported meals included meat, $S D=24.18, M d n=45.4$. Felt ambivalence (FA) correlated negatively with meat consumption frequency, $r(553)=-.18, p<$ .001 (see Figure 2). Unlike previous research (Armitage \& Arden, 2007), there were no significant curvilinear associations as indicated by planned contrasts, $p \mathrm{~s}>.05$. Controlling for covariates that remained significant after stepwise exclusions (i.e., gender, age, household size, and education, $p s<.05)$ the partial correlation of FA and meat consumption remained significant, $r(547)=-.14, p=.001$. An exploratory multiple regression tested whether the effect of FA on meat consumption remained significant after controlling for the evaluative components of the attitude that form the ambivalence, given that they can influence both FA and meat consumption. The effect of FA turned nonsignificant after including negativity, positivity, and potential ambivalence (PA), $\beta=-.02, p=.674$. Note that this test has been argued to be invalid as the covariates partial out parts of the target effect (Rohrer, 2018). Specifically, the causal effects of FA on affective states (Nohlen et al., 2019; van Harreveld, Rutjens, et al., 2009) play a crucial role in our conceptual model by affecting the desire to reduce ambivalence-induced discomfort through behavioral change. The lack of conclusiveness of this test highlights a need to gain better insight into the isolated role of FA using experimental methods (see Study 2 and 3).

\section{Figure 2}

Scatterplot of the association of felt ambivalence with meat consumption. 


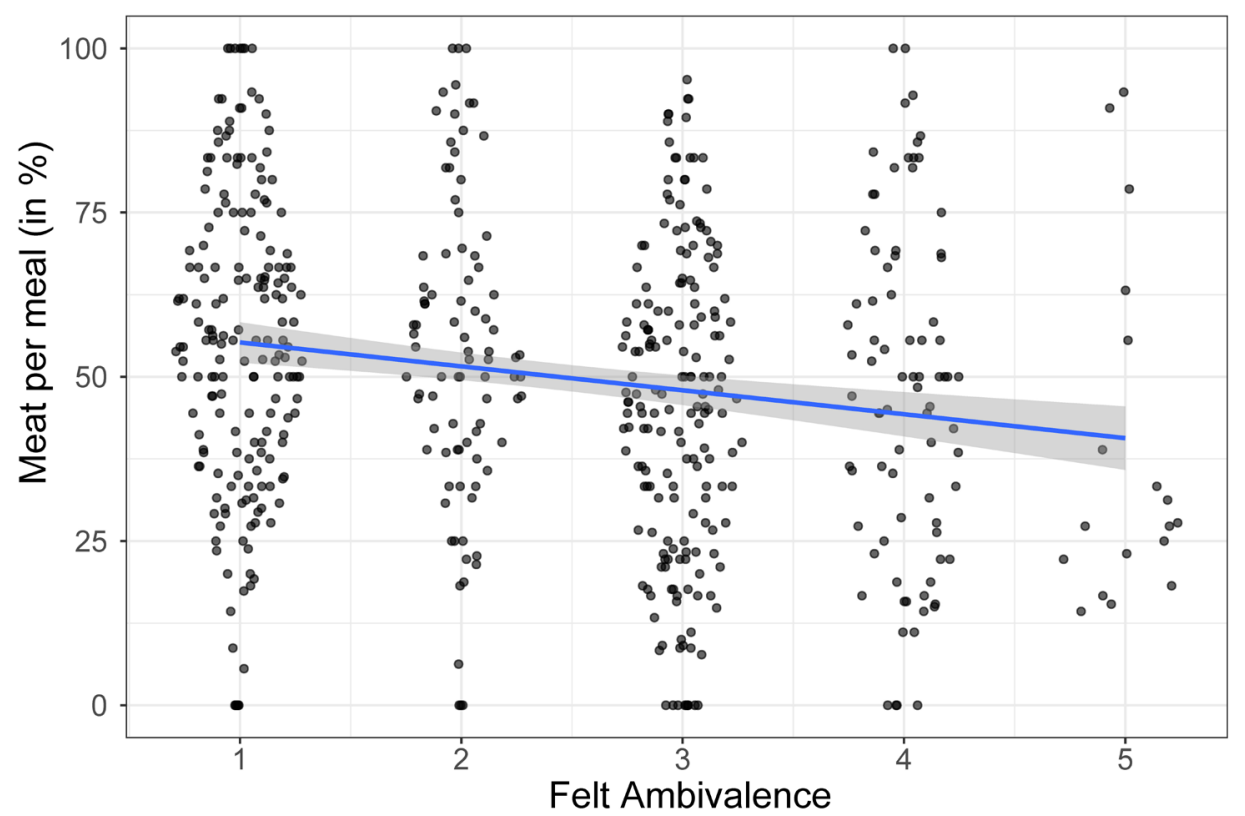

As predicted, a mediation analysis showed that there was an indirect effect of PA on meat consumption through FA, $\beta=-.05,95 \%$ CI $[-.09,-.01]$. There was a significant direct effects of FA, $\beta=-.12, p=.008$, on meat consumption. Next, multiple regression analyses supported the prediction that the aversive nature of ambivalence can drive meat reduction above the potential effect of a lack of perceived behavioral control in meat reduction on FA, as the association of FA with meat consumption remained significant above and beyond the effect of perceived control on meat consumption (see Table 3).

Table 3

Multiple regression results for meat consumption frequency.

Variable Model 1

Model 2

$\begin{array}{lll}B & S E\end{array}$

Constant

$0.59^{* *}$

0.02

$0.62^{* *}$

0.03

Felt ambivalence

$-0.04^{* *} \quad 0.01$

$-.18^{* *}$

$-0.03^{* *}$

0.01

$-.16^{* *}$

Behavioral control

$-0.03^{*} \quad 0.01$

$-.10^{*}$ 


$\begin{array}{lll}R^{2} & .03^{* *} & .04^{* *} \\ \Delta R^{2} & .03^{* *} & .01^{*} \\ & & \\ { }^{*} p<.05 .{ }^{* *} p<.001 . & & \end{array}$

These findings replicate a correlation of FA with meat consumption (Berndsen \& van der Pligt, 2004) using a high-quality sample and measure of meat consumption frequency that reduced self-selection and recall biases, for instance. Moreover, in line with our model of ambivalence-motivated meat reduction, the effect of PA on meat reduction was mediated by FA. And FA seems to lead to meat reduction rather than vice versa through the difficulty of reducing meat consumption (i.e., perceived control). These findings support our assumption that the aversive nature of experiences of ambivalence may motivate meat reduction.

\section{Study 2}

Study 1 suggests that the negative association of meat-related ambivalence with meat consumption might be driven by the aversive nature of ambivalence. Study 2 sheds light on the process through which ambivalence and meat avoidance are associated by experimentally manipulating felt ambivalence. Based on our model of ambivalence-motivated meat reduction (see Figure 1), we hypothesized that situations that bring to mind the pervasive nature of meta-cognitive awareness of ambivalence (i.e., felt ambivalence) should increase meat avoidance. We adopted a common procedure to make felt ambivalence salient by increasing the simultaneous accessibility of incongruent evaluations (Berrios et al., 2015a; Newby-Clark et al., 2002). Specifically, we asked participants to introspect on the inconsistent evaluations (i.e., potential ambivalence) that they hold (see van Harreveld et al., 2014). This manipulation elicits felt ambivalence without necessarily impacting on the magnitude of potential ambivalence, as inconsistent evaluative components are relatively stable, whereas the magnitude of felt ambivalence depends on situational contexts (Berrios et 
al., 2015a; van Harreveld, van der Pligt, et al., 2009). As mentioned earlier, however, the elicitation of felt ambivalence may cause aversive states, such as anticipated regret, that drive the desire to resolve ambivalence (see van Harreveld, van der Pligt, et al., 2009), such as through ambivalence-induced negative judgments of the attitude object (Nohlen et al., 2019)..

We measured behavioral intentions as the proximal determinant of meat avoidance.

We deemed intentions to be a sufficiently adequate proxy based on meta-analytic evidence on experimentally-induced intentions often leading to actual behavioral change (Rhodes \&

Dickau, 2012). We included a reverse-coded intention item to account for the possibility that meat-related conflict could be resolved through whatever coping opportunity is afforded (see Stone et al., 1997; Tian et al., 2016).

In addition to a self-report measure of intended meat avoidance as an outcome of ambivalence toward meat, we administered a charitable donation task. This was included to provide converging evidence for ambivalence-motivated behavioral change on a personally relevant choice instrument that reduces hypothetical bias (Bohm, 1972; Murphy et al., 2005). Moreover, a significant experimental effect on both intention and donation would rebut the possibility that participants cope with feeling conflicted merely through the affordance that is provided first (see Aronson et al., 1995; Stone et al., 1997).

\section{Method}

\section{Participants and Design}

The final sample of 189 participants mainly from North America $\left(90.0 \%, M_{\mathrm{age}}=\right.$ $35.81, S D=11.28,63.5 \%$ female, $54.5 \%$ with university degrees) was recruited through MTurk. We excluded 13 participants $(6.4 \%)$ who failed predetermined quality checks by duplicate participation or failing an adapted instructional attention check (Oppenheimer et al., 2009). As predetermined, a total of 12 people who followed meat-free diets were excluded from data analyses given that they could not further reduce their meat consumption. The 
study employed a two-group between-subjects design. We targeted at an a priori determined sample size of 172 valid cases to detect an expected effect size of $d=0.50$ (Berrios et al., 2015a) at an alpha level of .05 with a power of $90 \%$.

\section{Materials and Procedure}

Participants were invited to a study on "everyday life behavior". They were randomly assigned to an introspective ambivalence manipulation task about eating meat or an unrelated control issue (vaccination). Subsequently, they answered questions on potential and felt ambivalence, intentions, charitable donation, and sociodemographics.

Ambivalence Manipulation. We elicited ambivalence about eating meat using an introspective ambivalence manipulation procedure (adapted from Berrios et al., 2015b; van Harreveld et al., 2014). This ecologically valid procedure has frequently been used to make felt ambivalence salient by having participants introspect on their preexisting incongruent evaluations or personal experiences, and thus increase the simultaneous accessibility of attitudinal inconsistency (see Berrios et al., 2015a for a meta-analysis; Newby-Clark et al., 2002). Participants were asked to describe two personally held reactions in favor of and two reactions opposed to meat consumption or vaccination in the control group:

"We would like to know your arguments/feelings in favor of and against meat consumption [vaccination]. Please think about meat consumption [vaccination] and, firstly, write down your 2 strongest arguments/feelings in favor of meat consumption [vaccination] and, secondly, your 2 strongest arguments/feelings against meat consumption [vaccination]. The aim of this task is to assess your personal experiences and preferences."

Felt Ambivalence. Meta-cognitive awareness of ambivalence about eating meat was measured using the Felt Ambivalence Questionnaire (Priester \& Petty, 1996), which is based on the tripartite model of attitudes (e.g., Ostrom, 1969). The instrument measures the 
affective, behavioral, and cognitive components of experiences of ambivalence. It encompasses three items that read "Toward eating meat I..." with 10-point response scales ranging from feel no conflict at all/feel no indecision at all/have completely one-sided reactions to maximum conflict/maximum indecision/completely mixed reactions. Internal reliability was good, $\alpha=.87$.

Potential Ambivalence, negativity, and positivity. These variables were measured as in Study 1 but on 10-point response scales $(r=-.66)$.

Behavioral Intention. Intention to reduce meat consumption was assessed on two items (adapted from Graça, Calheiros, et al., 2015; Rees et al., 2018): "I intend to reduce my meat consumption next week", and "I will maintain my current levels of meat consumption in the future" (reverse-coded) on scales from 1 (strongly disagree) to 11 (strongly agree), $r=$ .76.

Charitable Donation. Participants were told that they qualified for a bonus payment drawing of 10 USD for passing the attention check item presented on the preceding page. They could type in any donation amount that we would donate if they did not want to receive the complete bonus. The charity was "an animal advocacy organization trying to reform the way farmed animals are treated" (see Supporting Information for details).

Meat Consumption Frequency. For the purpose of excluding strict meat avoiders and to rule out heterogeneous treatment effects, participants were asked to write down either the average times per day or the days per week, month, or year that they consumed meat (see Supporting Information).

\section{Results \& Discussion}

Regression coefficients are in standardized format. CIs are based on 5,000 bootstrap samples in mediation analyses. There were no significant confounders or heterogeneous treatment effects of the experimental manipulation, $p \mathrm{~s}>.17$. 
The manipulation checks showed that meat-related ambivalence salience (AS) successfully elicited felt ambivalence toward eating meat (FA). A between subjects ANOVA indicated that FA was higher in the AS condition $(M=4.70, S D=2.47, n=100)$ compared to the control $(M=3.87, S D=2.45, n=89), F(1,187)=5.28, p=.023, d=0.34$. Controlling for potential ambivalence (PA) as well as negative and positive associations to meat, the effect of AS on FA remained significant, $F(1,184)=4.51, p=.035, d=0.31$. As predicted, there was no significant effect of AS on PA, $F(1,187)=0.24, p=.625, d=0.07$, or positive evaluation, $F(1,187)=0.14, p=.709, d=0.06$. The experimental effect on negative evaluation of meat reached significance, $F(1,187)=4.87, p=.029, d=0.32$, but, crucially, turned nonsignificant, $F(1,186)=1.12, p=.291, d=0.16$, after including FA as a covariate. The manipulation checks therefore indicate that AS successfully elicited FA by making participants' preexisting evaluative incongruence salient without increasing PA, in accordance with previous research (Berrios et al., 2015a; Newby-Clark et al., 2002; van Harreveld et al., 2014). Importantly, the effect of the manipulation on FA remained significant after controlling for potentially confounding effects of PA, negativity, and positivity. Congruently, the effect of the manipulation on negativity was completely explained by FA - in other words, the experimentally-elicited FA increased ambivalent discomfort, which replicates previous research on ambivalence causing negativity, including anticipated regret and negative judgements (Nohlen et al., 2019; van Harreveld, Rutjens, et al., 2009; van Harreveld, van der Pligt, et al., 2009). Thus, the experimental manipulation was successful in eliciting FA rather than negativity.

AS significantly increased behavioral intention to reduce meat consumption $(M=$ $4.19, S D=2.72)$ compared to the control condition $(M=3.26, S D=2.27), F(1,187)=6.42, p$ $=.012, d=0.37$. An exploratory ANCOVA isolated the role of FA in the effect of AS on intention from potentially confounding effects of AS on evaluative components that might 
influence FA. That is, the effect of AS on intention remained significant, $\mathrm{F}(1,184)=4.14, p=$ .043, after including PA, negativity, and positivity as covariates. Note that this usage of ANCOVAs has been argued to be invalid given that the covariates partial out parts of the target effect (Rohrer, 2018), i.e., the causal effects of FA on affective states (see van Harreveld, van der Pligt, et al., 2009). While we deem the manipulation checks more conclusive, the isolated effect of AS on intention further strengthens confidence in the effect of AS on intention.

As hypothesized, a mediation analysis (Hayes, 2013/2018) indicated a positive indirect effect of AS on intention through FA, $\beta=.17, S E=.08,95 \%$ CI $[.02, .32]$, such that the direct effect of AS turned nonsignificant (see Figure 3). Two ANOVAs showed that the experimental effect on intention held irrespective of non-target coping opportunities afforded by the directions of the two intention items, as there were stronger intentions to reduce meat consumption in $\operatorname{AS}(M=4.15, S D=2.83)$ compared to the control condition $(M=3.11, S D=$ $2.41), F(1,187)=7.27, p=.008, d=0.39$, and lower intentions to maintain the current level of meat consumption $(M=7.77, S D=2.93)$ compared to the control condition $(M=8.60, S D$ $=2.55), F(1,187)=4.23, p=.041, d=0.30$. However, charitable donation was not significantly increased by AS $(M=1.93, S D=2.23)$ compared to the control condition $(M=$ $1.79, S D=2.16), F(1,187)=0.20, p=.655, d=0.07$. 


\section{Figure 3}

Mediation model of the experimental effect of meat ambivalence salience on intention to eat less meat through felt ambivalence in Study 2. Effect sizes are displayed as standardized direct effects (i.e., isolated from the other effects).

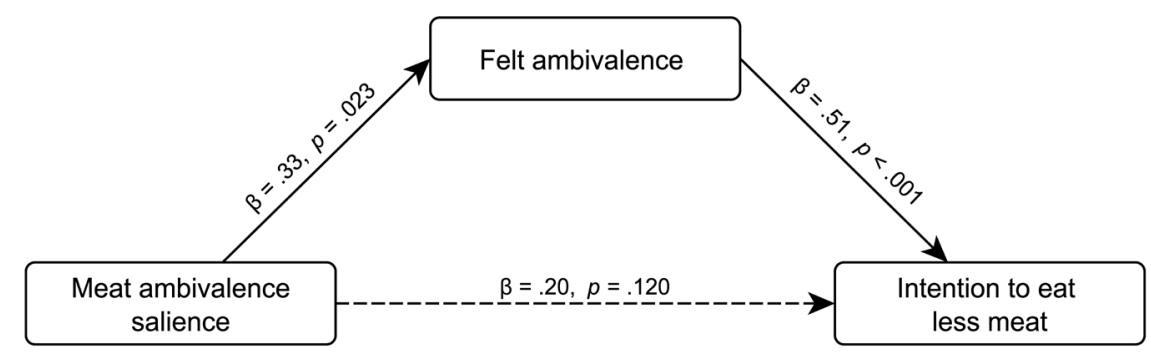

The findings indicate that AS increased meat avoidance as an effect of FA. This supports the assumption that the aversive nature of meat-related ambivalence can motivate meat avoidance, arguably due to anticipated ambivalence reduction. Contradictory to our predictions, however, there was no significant effect of AS on charitable donation, which might possibly be due to offering donation to an animal advocacy NGO instead of a donation opportunity that addresses all prevalent components of meat ambivalence.

\section{Study 3}

In Study 3 (preregistered), we primarily aimed to replicate the experimental effects observed in Study 2 and expand on the mechanisms involved in ambivalence-motivated meat reduction. We preregistered the hypotheses that ambivalence salience increases felt ambivalence toward meat, which predicts meat avoidance through increasing the perceived potential of meat avoidance to resolve the ambivalence. This, in turn, motivates effortful information-seeking (see Figure 1 for a conceptual model). Our central tenet is that the salience of the pervasive experience of ambivalence leads to meat avoidance. This is based on the assumption that alleviating the ambivalent discomfort through other coping strategies, such as moral disengagement (e.g., Bastian et al., 2012), would afford only temporary, and 
thus less effective, coping opportunities once someone has developed a chronically recurring awareness of the conflict. Meat avoidance could be motivated to alleviate the aversive nature of meat ambivalence and prevent feelings of conflict from recurring.

We aimed to directly examine the motivational underpinning of ambivalence-induced meat reduction by assessing the perceived potential of meat avoidance to reduce felt ambivalence. We predicted an indirect effect of AS on meat avoidance through this variable. Moreover, this effect could indicate a twofold process toward meat avoidance. Firstly, anticipated ambivalence resolution might directly motivate meat avoidance as a way of reducing chronic ambivalence. It may also motivate effortful information seeking to regain a univalent attitude and increase the feasibility of meat avoidance, for instance through learning about plant-based meat-alternatives. As an additional mechanism, Study 3 therefore tested whether anticipated ambivalence resolution predicts meat avoidance through information seeking.

Given that Study 2 did not yield a significant experimental effect on charitable donation, we adjusted the donation instrument to incorporate an NGO that addresses the most prevalent components of meat ambivalence. These components were identified in an ancillary content-analysis of the introspective evaluations obtained from Study 2 - i.e., health benefits and risks, animal ethics, sustainability, and sensory pleasure (see Supporting Information). This measure was aimed to provide converging evidence for ambivalence-motivated behavioral change using a performance-based instrument that reduces hypothetical bias (Bohm, 1972; Murphy et al., 2005), and rule out the possibility that participants cope with feeling conflicted merely through the affordance that is provided first (see Aronson et al., 1995; Stone et al., 1997). 


\section{Method}

\section{Participants}

A final sample size of 448 participants from England $\left(M_{\text {age }}=35.05, S D=12.16\right.$, $58.7 \%$ female, $60.7 \%$ with university degrees) was recruited through Prolific. A total of 20 participants were excluded due to failing preregistered quality checks, namely less than 2 seconds median speed per item (Huang et al., 2012) and attention checks (i.e., noncompliance in an open-ended question, and 'Could you please select 'very much' as a check of your attention?”). As preregistered, a total of 12 people who followed meat-free diets were not included in the analyses as they could not further reduce their meat consumption.

We preregistered a target sample size of 452 valid cases based on a two-group between-subjects design. This sample size provides $80 \%$ power to detect effect sizes of $d \mathrm{~s}>$ 0.265 on the behavioral outcomes at an alpha level of .05 . The preregistration document can be found at osf.io/7w69j.

\section{Materials and Procedure}

Participants were randomly assigned to an introspective ambivalence manipulation task concerning meat consumption or an unrelated control topic (going to the cinema). Due to a technical problem, 222 participants had to be excluded from the analyses and were replaced by collecting data from the same number of new participants. Specifically, they were not presented with one of the preregistered experimental manipulations due to a coding error. Consequently, the randomization allocation had to be adjusted during data collection, which is a permissible change (Altman, 2018) as the complete dataset was recorded within 3 hours without inducing relevant allocation biases (see Supporting Information for details).

Ambivalence Manipulation \& Felt Ambivalence. We elicited felt ambivalence about eating meat as in Study 2 (with streamlined and revised instructions, see Supporting 
Information). Felt ambivalence was measured as in Study 2 but on 7-point response scales ( $\alpha$ $=.84)$.

Potential Ambivalence, negativity, positivity. As in Study 1 and 2, two split semantic differential scales (Kaplan, 1972) measured positive and negative associations to eating meat on 7-point response scales ranging from not at all positive[/negative] to extremely positive[/negative]: "Considering only the positive[/negative] aspects of meat consumption, while ignoring the negative[/positive] aspects, how positive[/negative] are your thoughts and/or feelings regarding meat consumption?" ( $r=-.28)$. Thompson et al. (1995)'s score of potential ambivalence was calculated as in Study 1.

Anticipated Ambivalence Resolution. We measured the perceived potential of meat avoidance to reduce felt ambivalence with three questions (adapted from Clark et al., 2008) that are based on a tripartite model of attitudes (e.g. Ostrom, 1969): "To what extent do you believe that choosing to eat less meat would help you resolve any [conflicted feelings, indecision, mixed reaction] you may have about eating meat?". The response scales ranged from 1 (not at all) to 7 (very much), $\alpha=.95$.

Behavioral Intention. Intention to eat less meat was assessed on two items (adapted from Graça et al., 2015; Rees et al., 2018): “To what extent are you willing to reduce your meat consumption?", and "Do you intend to follow a more plant-based diet within the next year?" $(\alpha=.88)$.

Charitable Donation. Donation was assessed as in Study 2, but the charity was "The Good Food Institute, an NGO that develops healthy and sustainable alternatives to animalbased meat that make plant-based food choices easier".

Information Seeking. Information seeking about plant-based foods was measured in a choice setting. Participants were told that they would read one out of three articles on the next page, which would be chosen based on their interest in the three topics: "The easiest ways to 
transition to reduced-meat diets", "How to prepare tasty plant-based meals", "What to eat more of if you're eating less meat". The response scales ranged from 1 (not at all) to 7 (very $m u c h), \alpha=.84$. All participants were subsequently presented with recommendations for plant-based eating from Health Canada and reading time was assessed by TaskMaster (Permut et al., 2019). However, there were no significant effects on reading time due to low compliance (see Supporting Information).

Meat Consumption Frequency. We adjusted the assessment of meat consumption frequency in order to reduce biased recall (see Schwarz, 1999). Participants entered the number of "lunch and dinner meals that you usually eat in a regular week, for instance last week, that contain meat" (adapted from Graça et al., 2019; see Supporting Information for details).

\section{Results \& Discussion}

In this section, we firstly address confounders and heterogeneous treatment effects, followed by a report of the effects of the experimental manipulation of felt ambivalence and, thirdly, mediation analyses.

\section{Confounders and heterogeneous treatment effects}

Gender and education emerged as significant confounders $(p \mathrm{~s}<.05)$ in most treatment effects as they were associated with meat ambivalence and meat consumption (see also Study 1 and meta-analytic evidence in Berrios et al., 2015a). Exploratory moderation analyses revealed that there were no significant heterogeneous treatment effects, $p \mathrm{~s}>.08 .{ }^{3} \mathrm{We}$ therefore report all findings controlling for these covariates if not stated otherwise, in accordance with the preregistration.

\footnotetext{
${ }^{3}$ We do not discuss the marginally significant effect of $p=.08$ because the test for heterogenous treatment effects was exploratory.
} 
The absence of significant confounding effects in Study 2 might possibly be explained by a larger and more educated, but less female sample in Study 3 (see Berrios et al., 2015a). The absence of significant heterogeneous treatment effects replicates Study 2 but not previous research (e.g., Dowsett et al., 2018). One potential explanation might be a low experimenter demand effect in our experimental procedure, whereas merely announcing a video presentation related to farmed animal suffering has been shown to diminish meat commitment in females (Rothgerber, 2018).

\section{Experimental effects}

As in Study 2, the experimental manipulation of meat-related ambivalence salience (AS) successfully elicited felt ambivalence toward eating meat (FA) as indicated by the following manipulation checks. An ANCOVA showed that FA was higher in the meat ambivalence salience condition (AS; $n=232)$ compared to the control condition $(n=216)$, $M_{\mathrm{adj}}(\mathrm{AS})=3.62, M_{\mathrm{adj}}(\mathrm{control})=3.14, S E=.09, F(1,444)=15.19, p<.001, d=0.35$. Additional tests (not preregistered) revealed that the effect of AS on FA remained significant after controlling for potential ambivalence (PA) as well as its components, i.e., negative and positive associations to meat consumption, $F(1,443)=11.79, p<.001$. There was no significant effect of AS on PA, $F(1,444)=2.11, p=.147, d=0.14$, or positivity, $F(1,444)=$ $0.16, p=.694, d=0.04$. The experimental effect on negativity reached significance, $F(1,444)$ $=4.04, p=.045, d=0.19$, but turned nonsignificant, $F(1,444)=0.01, p=.919, d=0.01$, after including FA as a covariate.

These manipulation checks replicate results from Study 2 by indicating that AS successfully elicited FA by making participants' preexisting evaluative incongruence salient without increasing PA, in line with previous research (Berrios et al., 2015a; Newby-Clark et al., 2002; van Harreveld et al., 2014). Again, the effect of the manipulation on FA remained significant after controlling for potentially confounding effects of PA, negativity, and 
positivity. Congruently, the effect of the manipulation on negativity was completely explained by FA - in other words, the experimentally-elicited FA increased ambivalent discomfort, which replicates also previous research on ambivalence causing negative affect and judgment (Nohlen et al., 2019; van Harreveld, Rutjens, et al., 2009; van Harreveld, van der Pligt, et al., 2009). Thus, the experimental manipulation was successful in eliciting FA rather than negativity.

As hypothesized, AS increased anticipated ambivalence reduction, $M_{\text {adj }}(\mathrm{AS})=3.95$, $M_{\text {adj }}($ control $)=3.59, S E=.12, F(1,444)=4.66, p=.031, d=0.20$, and information seeking, $M_{\text {adj }}(\mathrm{AS})=4.70, M_{\mathrm{adj}}(\mathrm{control})=4.33, S E=.11, F(1,444)=5.81, p=.016, d=0.22$. The experimental effect on intention to eat less meat was marginally significant but in the same direction as the experimental effect on intention in Study $2, M_{\text {adj }}(\mathrm{AS})=4.18, M_{\text {adj }}($ control $)=$ $3.90, S E=.11, F(1,444)=3.27, p=.071, d=0.16$. Charitable donation was increased without significant confounders, $M(\mathrm{AS})=2.86, S D=2.72, M($ control $)=2.29, S D=2.55$, $F(1,447)=5.15, p=.024, d=0.22$.

Exploratory and non-preregistered ANCOVAs were aimed to further examine the role of FA in the effect of AS on the outcomes isolated from potentially confounding effects of AS on evaluative components of the attitude that forms the ambivalence. Specifically, after including PA, negativity, and positivity as covariates, the effects of AS remained significant for donation, $\mathrm{F}(1,443)=4.46, \mathrm{p}=.035$, and information seeking, $\mathrm{F}(1,441)=4.48, p=.035$. Unlike Study 1, the isolated effect of AS did not reach significance for intention, $F(1,441)=$ $1.16, p=.283$, and for anticipated ambivalence reduction, $\mathrm{F}(1,441)=1.99, p=.159$. Note, however, that this usage of ANCOVAs has been argued to be invalid given that the covariates partial out parts of the target effect (Rohrer, 2018). Specifically, felt ambivalence is an aversive state that influences affective and evaluative processes (Nohlen et al., 2019; van Harreveld, Rutjens, et al., 2009), which plays a crucial role in our conceptual model by 
affecting the desire to reduce ambivalence-induced discomfort through behavioral change. In light of the aforementioned and more conclusive manipulation checks, the two significant effects of AS after controlling for evaluative components further strengthen confidence in the pattern of effects of AS.

\section{Serial indirect effects}

Regression coefficients are in standardized format. Mediation analyses are based on 10,000 bootstrap samples. The preregistered serial mediation model was supported with a positive serial indirect effect of ambivalence salience on behavioral intentions through felt ambivalence, anticipated ambivalence resolution, and information seeking, $\beta=.03, S E=.01$, 95\% CI [.01, .05] (see Figure 4). The experimental effects of AS were successfully explained by the mediators such that they turned nonsignificant. The analysis revealed that the indirect effect solely through felt ambivalence, $\beta=.14, S E=.04,95 \%$ CI $[.06, .21]$, remained significant even after controlling for the other variables in the model. To also probe the other two simple indirect effects of AS on intention through each of the two mediators, we firstly run a parallel mediation analysis that revealed significant isolated simple indirect effects solely through anticipated ambivalence reduction, $\beta=.05, S E=.03,95 \% \mathrm{CI}[.01, .11]$, or information seeking, $\beta=.05, S E=.02,95 \% \mathrm{CI}[.01, .10]$. As a second and non-preregistered robustness check, two separate simple mediation models showed, again, significant indirect effects of AS on intention solely through anticipated ambivalence reduction, $\beta=.13, S E=$ $.06,95 \%$ CI $[.01, .25]$, or information seeking, $\beta=.13, S E=.05,95 \%$ CI $[.02, .24]$. Finally, when entering charitable donation as a performance-based outcome into the serial mediation model instead of intention, the same pattern of findings emerged with an indirect effect of AS on donation through the three mediators in serial, $\beta=.02, S E=.01,95 \%$ CI $[.01, .04]$.

\section{Figure 4}


Serial mediation model of ambivalence-motivated intention to eat less meat in Study 3. Effect sizes are displayed as standardized direct effects (i.e., isolated from the other effects).

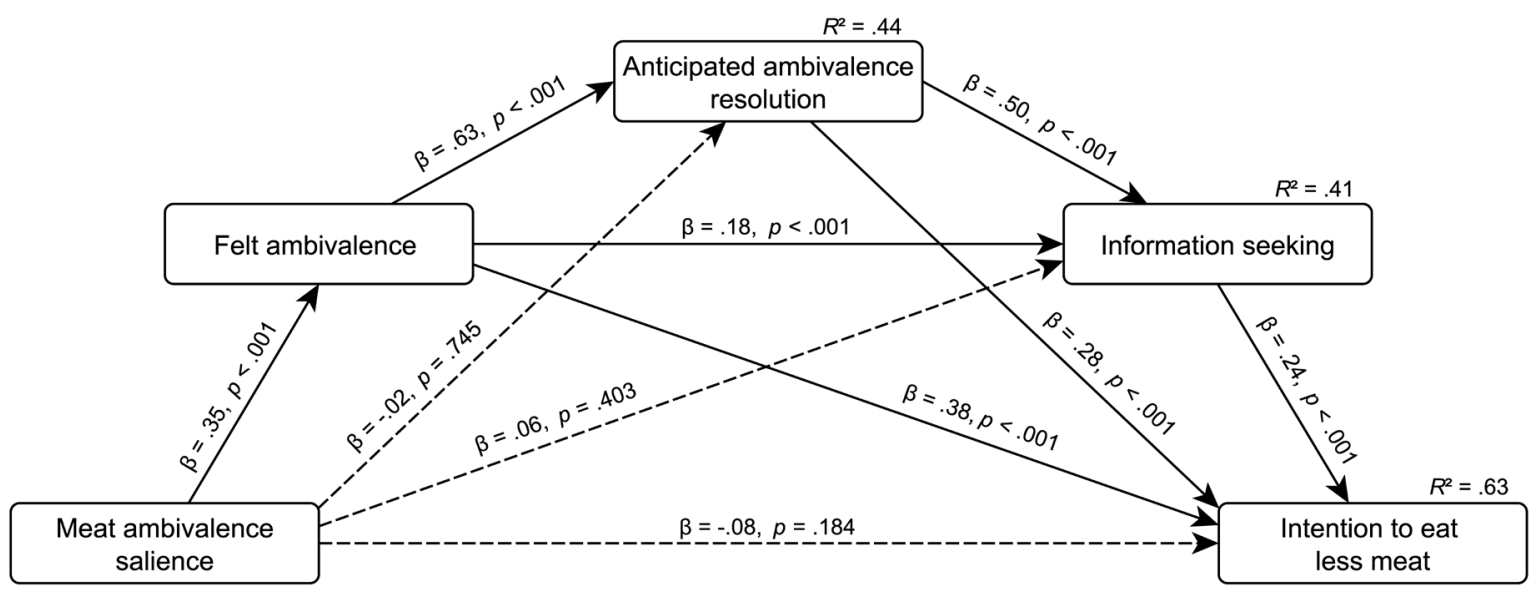

These findings substantiate our model of ambivalence-motivated meat reduction. The experimentally elicited salience of the aversive nature of meat ambivalence increased both meat reduction intention and charitable donation. This finding reduces the likelihood of nontarget effects such as an order effect or hypothetical bias. Moreover, mediation analyses provided initial support for potential roles of anticipated ambivalence reduction and information seeking in how meat ambivalence leads to meat avoidance. While the mediation analyses support our hypotheses, we do not claim that they warrant causal roles of the mediators (see Bullock et al., 2010). Likewise, the findings do not rule out alternative serial mediation orders, even though the order highlighted in the present work is based on ample prior research (e.g., Clark et al., 2008; Nordgren et al., 2006; Petty \& Cacioppo, 1986; van Harreveld et al., 2015).

\section{General Discussion}

The purpose of the current research was to investigate how meat-related ambivalence can motivate meat avoidance, and in doing so it makes several important contributions to research on ambivalence and the psychology of (not) eating meat. The studies showed that 
ambivalence can drive meat reduction through the motivation to alleviate the pervasive feelings of conflict. This finding adds to previous research that has indicated a correlation of ambivalence with self-reported (intention for) meat reduction (Amiot et al., 2020; Armitage \& Arden, 2007; Berndsen \& van der Pligt, 2004). We replicated this correlation using a diary study in the general public (Study 1) and investigated the causal direction and potential mechanisms of the association (Study 2 and 3). Our model of ambivalence-motivated meat reduction (see Figure 1) proposes that the pervasive nature of ambivalence can motivate meat avoidance and highlights two potential mechanisms involved: the anticipation of ambivalence reduction through behavioral change, and information seeking to facilitate behavioral change. The findings reveal that behavioral change can be a prevalent coping strategy that people may employ to resolve felt ambivalence in the context of meat consumption.

The findings of Study 1 revealed several sociodemographic predictors of meat-related ambivalence in a quota sample - i.e., gender, social context, employment status, and age. Gender and social context moderate the extent to which attitudinal inconsistency is reflected in an awareness of conflict. Specifically, a social circle with a high number of meat avoiders could possibly induce feelings of conflict in meat eaters despite low attitudinal inconsistency to enhance their social image in the social circle (Toribio-Flórez et al., 2020), and close others who follow a meat-free diet could possibly make an individual's attitudinal inconsistency salient (see De Groeve \& Rosenfeld, 2021). Interestingly, the predictors did not significantly impact on felt ambivalence at high potential ambivalence. This could indicate a primacy of potential ambivalence in leading to felt ambivalence regardless of the aforementioned individual differences. Thus, another important explanation could be that the individual differences influence a motivated avoidance of felt ambivalence only at low levels of potential ambivalence, such as if being male facilitates averting experiences of felt ambivalence only at some levels of PA but not at high PA. At high levels of potential 
ambivalence, however, it might become too difficult to avert felt ambivalence. Interestingly, sociodemographic variables did not significantly moderate the effects of meat ambivalence on behavioral change in the present set of studies. Gender, for example, therefore seems to influence the extent to which people experience conflict rather than how they react to it. This could arguably explain why previous research has not consistently found (the absence of) gender differences in the use of coping mechanisms related to meat consumption (e.g., Piazza et al., 2015, 2020).

Study 2 and 3 experimentally elicited felt ambivalence utilizing an ecologically valid introspection procedure (see Berrios et al., 2015a for a meta-analysis). This manipulation of felt ambivalence about meat consumption increased behavioral change, which was largely explained by the proposed mechanisms, i.e., anticipation of ambivalence reduction through eating less meat, and information seeking for facilitating meat reduction. Notably, manipulation checks show that the experimental procedure successfully elicited felt ambivalence about meat without influencing evaluative components of the attitude that form the ambivalence (i.e. positivity, negativity, and potential ambivalence). This finding indicates that the effect of felt ambivalence on meat reduction is not epiphenomenal. In other words, the aversiveness of felt ambivalence and not simply the evaluations inherent to ambivalence motivated meat reduction in our data. Confidence in felt ambivalence driving the effects is further strengthened by a large number of effects remaining significant even after controlling for the evaluative components that form meat ambivalence. A limitation of Study 2 and 3 is that we utilized intended meat reduction as an outcome but not actual meat consumption. However, experimentally induced behavioral intentions are an important predictor of behavior (see Rhodes \& Dickau, 2012 for a meta-analysis), and Study 3 supported the pattern of findings employing a performance-based outcome measure of charitable donation behavior, whereas Study 1 employed a robust 6-day diary of meat consumption. 
A novel intervention paradigm for empowering decision competence on healthy and sustainable food choices could encourage individuals to reflect on their chronic ambivalence about meat. The experimental manipulation of felt ambivalence in Study 2 and 3 elicited behavioral change merely by making felt ambivalence salient. This finding suggests that introspective ambivalence elicitation can complement persuasive intervention approaches that are commonly employed to facilitate meat reduction (Grundy et al., 2021; Harguess et al., 2020; Mathur et al., 2021). Interventional messages could prompt individuals to reflect on their personal conflicts between preexisting incongruent evaluations of meat consumption. This prompt may motivate them to reconcile the incongruent beliefs and obtain a more univalent attitude, such as through acquiring information on the practicalities of plant-based diets (e.g., Willett et al., 2019). Importantly, ambivalence-induced effortful elaboration can foster more persistent attitudinal and behavioral change (Petty \& Cacioppo, 1986; van Harreveld et al., 2015). As our data showed participants to hold opposing evaluations about health benefits and risks related to meat (see Supporting Information for the Ancillary Study), one major application concerns health messages that can include an elicitation of personally held ambivalence in addition to information that helps in resolving conflict about health implications of meat consumption.

Yet, at first glance, the finding that felt ambivalence can motivate meat reduction seems at odds with research on the "meat paradox" (Loughnan et al., 2010), which has drawn on cognitive dissonance theories (e.g., Festinger, 1957) to explain how meat consumption is maintained in light of detrimental consequences (Bastian \& Loughnan, 2016; Rothgerber \& Rosenfeld, 2021). Research on ambivalence and dissonance reflect methodologically and conceptually distinct frameworks (see Dalege et al., 2019). For one, research on meat-related dissonance focuses on situational conflicts between behavior and cognition, such as by presenting participants with messages about critical issues related to meat while increasing 
the salience of meat commitment (e.g., Bastian et al., 2012). In our set of studies, in contrast, felt ambivalence reflects a chronic awareness of experiences of conflict between stably held but incongruent evaluations of meat.

A promising avenue to further investigate ambivalence-motivated meat reduction may be cross-national and temporal differences in the association of meat ambivalence with attitudinal change and meat consumption. There are cross-national differences both in meat ambivalence (Ruby et al., 2016) and the different directions of meat consumption trends (de Boer \& Aiking, 2018; OECD \& FAO, 2020). The association of meat consumption with ambivalence could be tracked over time as attitudes toward meat change. In Switzerland, for example, people are increasingly concerned about the effects of meat consumption (Siegrist et al., 2015).

Another research question to investigate ambivalence-motivated meat reduction concerns whether meat avoidance successfully resolves ambivalence, given that the anticipation of ambivalence reduction through behavioral change plays a pivotal role in our model. From the context of low-fat diets (Armitage \& Arden, 2007), there is support for the idea that a stable low-fat diet is associated with less ambivalence compared to people who are transitioning toward this diet. Meat reduction could alleviate felt ambivalence over a certain amount of time after dietary change, as reduced meat consumption decreases the recurrence of ambivalent discomfort from conflicted food choice. Resolving potential ambivalence might require attitudinal change, however, such as through dissonance-reduction after behavioral change (e.g., Albarracín \& Wyer, 2000) or ambivalence-motivated information seeking. Given the potentially bidirectional association of ambivalence with behavioral change, previous correlational research has remained inconclusive regarding the direction of the association. The present studies substantiate our assertion that at least parts of the association is driven by a motivation to resolve the pervasive experience of ambivalence. 
Interestingly, it can nonetheless be assumed that also vegetarians and vegans feel some ambivalence about eating meat (van der Weele, 2013), for example due to a lack of social support by people who follow other dietary patterns (see Minson \& Monin, 2012). Future research could investigate the prevalence and evaluative components of this kind of meatrelated ambivalence, besides its possibly distinct impact on food choices.

The present research sheds light on the association of ambivalence with behavioral change in the context of meat consumption, revealing how the need to cope with meat-related ambivalence can motivate meat reduction. Our findings add to the growing body of literature on why some people eat less meat by highlighting the importance of the motivational consequences of ambivalence in eating less meat.

\section{Supplementary Material \& Data Availability Statement}

Data files, supporting information, and preregistrations are openly available in OSF at osf.io/7w69j, save the dataset from Study 1, which will be uploaded once an unrelated part of the dataset has been published in a separate article.

\section{Author contributions}

All authors have approved and contributed to the final manuscript. SP:

Conceptualization, Methodology, Data Analysis, Writing - Original Draft, Visualization, Funding Acquisition. BR: Conceptualization Study 3, Methodology Study 3, Writing Review \& Editing, Supervision. MR: Writing - Review \& Editing. GP: Conceptualization Study 1, Methodology Study 1, Writing - Review \& Editing, Funding Acquisition. FvH: Conceptualization, Methodology, Writing - Review \& Editing, Supervision.

\section{Conflicts of Interest}

The authors declare no conflicts of interest. 


\section{Acknowledgements}

Study 1 was funded by the Center for a Sustainable University and the Cluster of Excellence 'CliSAP' (EXC177), funded through the German Science Foundation (DFG), both at the University of Hamburg. Study 2 was funded by SP. Study 3 was funded by the University of Amsterdam. Preparation of this manuscript was facilitated by funding from the German Academic Scholarship Foundation to SP. We are grateful to Kai Epstude for feedback on parts of an earlier version of the manuscript as well as Irene Giovanetti and Elianne Prange for excellent assistance with qualitative content-analyses. 


\section{References}

Afshin, A., Sur, P. J., Fay, K. A., Cornaby, L., Ferrara, G., Salama, J. S., Mullany, E. C., Abate, K. H., Abbafati, C., Abebe, Z., Afarideh, M., Aggarwal, A., Agrawal, S., Akinyemiju, T., Alahdab, F., Bacha, U., Bachman, V. F., Badali, H., Badawi, A., ... Murray, C. J. L. (2019). Health effects of dietary risks in 195 countries, 1990-2017: A systematic analysis for the Global Burden of Disease Study 2017. The Lancet, 393(10184), 1958-1972. https://doi.org/10.1016/S0140$6736(19) 30041-8$

Ajzen, I., \& Madden, T. J. (1986). Prediction of goal-directed behavior: Attitudes, intentions, and perceived behavioral control. Journal of Experimental Social Psychology, 22(5), 453-474. https://doi.org/10.1016/0022-1031(86)90045-4

Albarracín, D., \& Wyer, R. S. (2000). The Cognitive Impact of Past Behavior: Influences on Beliefs, Attitudes, and Future Behavioral Decisions. Journal of Personality and Social Psychology, 79(1), 5-22.

Altman, D. G. (2018). Avoiding bias in trials in which allocation ratio is varied. Journal of the Royal Society of Medicine, 111(4), 143-144. https://doi.org/10.1177/0141076818764320

Amiot, C. E., Sukhanova, K., \& Bastian, B. (2020). Social identification with animals: Unpacking our psychological connection with other animals. Journal of Personality and Social Psychology, 118(5), 991-1017. https://doi.org/10.1037/pspi0000199

Anderson, C. J. (2003). The psychology of doing nothing: Forms of decision avoidance result from reason and emotion. Psychological Bulletin, 129(1), 139-167. https://doi.org/10.1037/00332909.129.1.139

Arbit, N., Ruby, M., \& Rozin, P. (2017). Development and validation of the meaning of food in life questionnaire (MFLQ): Evidence for a new construct to explain eating behavior. Food Quality and Preference, 59, 35-45. https://doi.org/10.1016/j.foodqual.2017.02.002

Armitage, C. J., \& Arden, M. A. (2007). Felt and Potential Ambivalence across the Stages of Change. Journal of Health Psychology, 12(1), 149-158. https://doi.org/10.1177/1359105307071749 
Armitage, C. J., \& Conner, M. (2000). Attitudinal Ambivalence: A Test of Three Key Hypotheses. Personality and Social Psychology Bulletin, 26(11), 1421-1432. https://doi.org/10.1177/0146167200263009

Aronson, J., Blanton, H., \& Cooper, J. (1995). From dissonance to disidentification: Selectivity in the self-affirmation process. Journal of Personality and Social Psychology, 68(6), 986-996. https://doi.org/10.1037/0022-3514.68.6.986

Bastian, B. (2019). Changing Ethically Troublesome Behavior: The Causes, Consequences, and Solutions to Motivated Resistance. Social Issues and Policy Review, 13(1), 63-92. https://doi.org/10.1111/sipr.12048

Bastian, B., \& Loughnan, S. (2016). Resolving the meat-paradox: A motivational account of morally troublesome behavior and its maintenance. Personality and Social Psychology Review, 1088868316647562.

Bastian, B., Loughnan, S., Haslam, N., \& Radke, H. R. M. (2012). Don't mind meat? The denial of mind to animals used for human consumption. Personality and Social Psychology Bulletin, 38(2), 247-256. http://psp.sagepub.com/content/38/2/247.short

Becker, D., Jostmann, N. B., Hofmann, W., \& Holland, R. W. (2019). Spoiling the pleasure of success: Emotional reactions to the experience of self-control conflict in the eating domain. Emotion, 19(8), 1377-1395. https://doi.org/10.1037/emo0000526

Berndsen, M., \& van der Pligt, J. (2004). Ambivalence towards meat. Appetite, 42(1), 71-78. https://doi.org/10.1016/S0195-6663(03)00119-3

Berrios, R., Totterdell, P., \& Kellett, S. (2015a). Eliciting mixed emotions: A meta-analysis comparing models, types, and measures. Frontiers in Psychology, 6. https://doi.org/10.3389/fpsyg.2015.00428

Berrios, R., Totterdell, P., \& Kellett, S. (2015b). Investigating goal conflict as a source of mixed emotions. Cognition and Emotion, 29(4), 755-763. https://doi.org/10.1080/02699931.2014.939948 
Bohm, P. (1972). Estimating demand for public goods: An experiment. European Economic Review, 3(2), 111-130. https://doi.org/10.1016/0014-2921(72)90001-3

Brug, J., van Assema, P., Kok, G., Lenderink, T., \& Glanz, K. (1994). Self-rated dietary fat intake: Association with objective assessment of fat, psychosocial factors, and intention to change. Journal of Nutrition Education, 26(5), 218-223. https://doi.org/10.1016/S0022$3182(12) 80890-9$

Bullock, J. G., Green, D. P., \& Ha, S. E. (2010). Yes, but what's the mechanism? (Don't expect an easy answer). Journal of Personality and Social Psychology, 98(4), 550-558. https://doi.org/10.1037/a0018933

Buttlar, B., Rothe, A., Kleinert, S., Hahn, L., \& Walther, E. (2021). Food for Thought: Investigating Communication Strategies to Counteract Moral Disengagement Regarding Meat Consumption. Environmental Communication, 15(1), 55-68. https://doi.org/10.1080/17524032.2020.1791207

Buttlar, B., \& Walther, E. (2018). Measuring the meat paradox: How ambivalence towards meat influences moral disengagement. Appetite, 128, 152-158. https://doi.org/10.1016/j.appet.2018.06.011

Buttlar, B., \& Walther, E. (2019). Dealing with the meat paradox: Threat leads to moral disengagement from meat consumption. Appetite, 137, 73-80. https://doi.org/10.1016/j.appet.2019.02.017

Buttlar, B., \& Walther, E. (2022). Escaping from the meat paradox: How morality and disgust affect meat-related ambivalence. Appetite, 168, 105721. https://doi.org/10.1016/j.appet.2021.105721

Clark, J. K., Wegener, D. T., \& Fabrigar, L. R. (2008). Attitudinal Ambivalence and Message-Based Persuasion: Motivated Processing of Proattitudinal Information and Avoidance of Counterattitudinal Information. Personality and Social Psychology Bulletin, 34(4), 565-577. https://doi.org/10.1177/0146167207312527 
Conner, M., Povey, R., Sparks, P., James, R., \& Shepherd, R. (2003). Moderating role of attitudinal ambivalence within the theory of planned behaviour. British Journal of Social Psychology, 42(1), 75-94. https://doi.org/10.1348/014466603763276135

Conner, M., Sparks, P., Povey, R., James, R., Shepherd, R., \& Armitage, C. J. (2002). Moderator effects of attitudinal ambivalence on attitude-behaviour relationships. European Journal of Social Psychology, 32(5), 705-718. https://doi.org/10.1002/ejsp.117

Dalege, J., Borsboom, D., van Harreveld, F., \& van der Maas, H. L. J. (2019). The Attitudinal Entropy (AE) Framework as a General Theory of Individual Attitudes. Psychological Inquiry, 29(4), 175-193. https://doi.org/10.1080/1047840X.2018.1537246

de Boer, J., \& Aiking, H. (2018). Prospects for pro-environmental protein consumption in Europe: Cultural, culinary, economic and psychological factors. Appetite, 121, 29-40. https://doi.org/10.1016/j.appet.2017.10.042

de Boer, J., Schösler, H., \& Boersema, J. J. (2013). Climate change and meat eating: An inconvenient couple? Journal of Environmental Psychology, 33, 1-8. https://doi.org/10.1016/j.jenvp.2012.09.001

De Groeve, B., \& Rosenfeld, D. L. (2021). Morally admirable or moralistically deplorable? A theoretical framework for understanding character judgments of vegan advocates. Appetite, 168, 105693. https://doi.org/10.1016/j.appet.2021.105693

Dowsett, E., Semmler, C., Bray, H., Ankeny, R. A., \& Chur-Hansen, A. (2018). Neutralising the meat paradox: Cognitive dissonance, gender, and eating animals. Appetite, 123, 280-288. https://doi.org/10.1016/j.appet.2018.01.005

Emmons, R. A., \& King, L. A. (1988). Conflict Among Personal Strivings: Immediate and Long-Term Implications for Psychologicaland Physical Well-Being. Journal of Personality \& Social Psychology, 54(6), 1040-1048. 
Eschenbeck, H., Kohlmann, C.-W., \& Lohaus, A. (2007). Gender Differences in Coping Strategies in Children and Adolescents. Journal of Individual Differences, 28(1), 18-26. https://doi.org/10.1027/1614-0001.28.1.18

Federal Ministry of Food and Agriculture. (2016). Deutschland, wie es isst. Der BMELErnährungsreport. Bonifatius.

Festinger, L. (1957). A theory of cognitive dissonance. Stanford University Press.

Gaspar, R., Luís, S., Seibt, B., Lima, M. L., Marcu, A., Rutsaert, P., Fletcher, D., Verbeke, W., \& Barnett, J. (2016). Consumers' avoidance of information on red meat risks: Information exposure effects on attitudes and perceived knowledge. Journal of Risk Research, 19(4), 533-549. https://doi.org/10.1080/13669877.2014.1003318

Godfray, H. C. J., Aveyard, P., Garnett, T., Hall, J. W., Key, T. J., Lorimer, J., Pierrehumbert, R. T., Scarborough, P., Springmann, M., \& Jebb, S. A. (2018). Meat consumption, health, and the environment. Science, 361(6399), eaam5324. https://doi.org/10.1126/science.aam5324

Graça, J., Calheiros, M. M., \& Oliveira, A. (2015). Attached to meat? (Un)Willingness and intentions to adopt a more plant-based diet. Appetite, 95, 113-125. https://doi.org/10.1016/j.appet.2015.06.024

Graça, J., Calheiros, M. M., \& Oliveira, A. (2016). Situating moral disengagement: Motivated reasoning in meat consumption and substitution. Personality and Individual Differences, 90, 353-364. https://doi.org/10.1016/j.paid.2015.11.042

Graça, J., Calheiros, M. M., Oliveira, A., \& Milfont, T. L. (2018). Why are women less likely to support animal exploitation than men? The mediating roles of social dominance orientation and empathy. Personality and Individual Differences, 129, 66-69. https://doi.org/10.1016/j.paid.2018.03.007

Graça, J., Truninger, M., Junqueira, L., \& Schmidt, L. (2019). Consumption orientations may support (or hinder) transitions to more plant-based diets. Appetite, 140, 19-26. https://doi.org/10.1016/j.appet.2019.04.027 
Grundy, E. A. C., Slattery, P., Saeri, A. K., Watkins, K., Houlden, T., Askin, H., Lee, J., Mintoft-Jones, A., Cyna, S., Dziegielewski, A., Gelber, R., Rowe, A., Mathur, M. B., Timmons, S., Zhao, K., Wilks, M., Harris, J., Rosenfeld, D. L., Bryant, C., ... Australia, B. (2021). Interventions that Influence Animal-Product Consumption: A Meta-Review. 49. https://doi.org/10.31219/osf.io/mcdsq

Hampel, P., \& Petermann, F. (2005). Age and Gender Effects on Coping in Children and Adolescents. Journal of Youth and Adolescence, 34(2), 73-83. https://doi.org/10.1007/s10964-005-3207-9

Harguess, J. M., Crespo, N. C., \& Hong, M. Y. (2020). Strategies to reduce meat consumption: A systematic literature review of experimental studies. Appetite, 144, 104478. https://doi.org/10.1016/j.appet.2019.104478

Hartmann, C., Dohle, S., \& Siegrist, M. (2013). Importance of cooking skills for balanced food choices. Appetite, 65, 125-131. https://doi.org/10.1016/j.appet.2013.01.016

Hartmann, C., \& Siegrist, M. (2020). Our daily meat: Justification, moral evaluation and willingness to substitute. Food Quality and Preference, 80, 103-799. https://doi.org/10.1016/j.foodqual.2019.103799

Hayes, A. F. (2013). Introduction to mediation, moderation, and conditional process analysis: A regression-based approach. The Guilford Press.

Haynes, A., \& Robinson, E. (2019). Who are we testing? Self-selection bias in laboratory-based eating behaviour studies. Appetite, 141, 104330. https://doi.org/10.1016/j.appet.2019.104330

Hofmann, W., Baumeister, R. F., Förster, G., \& Vohs, K. D. (2012). Everyday temptations: An experience sampling study of desire, conflict, and self-control. Journal of Personality and Social Psychology, 102(6), 1318-1335. https://doi.org/10.1037/a0026545

Huang, J. L., Curran, P. G., Keeney, J., Poposki, E. M., \& DeShon, R. P. (2012). Detecting and Deterring Insufficient Effort Responding to Surveys. Journal of Business and Psychology, 27(1), 99-114. https://doi.org/10.1007/s10869-011-9231-8

IJzerman, H., Lewis, N. A., Przybylski, A. K., Weinstein, N., DeBruine, L., Ritchie, S. J., Vazire, S., Forscher, P. S., Morey, R. D., Ivory, J. D., \& Anvari, F. (2020). Use caution when applying 
behavioural science to policy. Nature Human Behaviour. https://doi.org/10.1038/s41562020-00990-w

Itzchakov, G., \& van Harreveld, F. (2018). Feeling torn and fearing rue: Attitude ambivalence and anticipated regret as antecedents of biased information seeking. Journal of Experimental Social Psychology, 75, 19-26. https://doi.org/10.1016/j.jesp.2017.11.003

Jonas, K., Diehl, M., \& Brömer, P. (1997). Effects of Attitudinal Ambivalence on Information Processing and Attitude-Intention Consistency. Journal of Experimental Social Psychology, 33(2), 190-210. https://doi.org/10.1006/jesp.1996.1317

Kaplan, K. J. (1972). On the ambivalence-indifference problem in attitude theory and measurement: A suggested modification of the semantic differential technique. Psychological Bulletin, 77(5), 361-372. https://doi.org/10.1037/h0032590

Keller, C., \& Siegrist, M. (2015). Ambivalence toward palatable food and emotional eating predict weight fluctuations. Results of a longitudinal study with four waves. Appetite, 85, 138-145. https://doi.org/10.1016/j.appet.2014.11.024

King, L. A., \& Emmons, R. A. (1990). Conflict over emotional expression: Psychological and physical correlates. Journal of Personality and Social Psychology, 58(5), 864-877. https://doi.org/10.1037/0022-3514.58.5.864

Lea, E. J., Crawford, D., \& Worsley, A. (2006). Public views of the benefits and barriers to the consumption of a plant-based diet. European Journal of Clinical Nutrition, 60(7), 828-837. https://doi.org/10.1038/sj.ejcn.1602387

Loughnan, S., Bastian, B., \& Haslam, N. (2014). The Psychology of Eating Animals. Current Directions in Psychological Science, 23(2), 104-108. https://doi.org/10.1177/0963721414525781

Loughnan, S., Haslam, N., \& Bastian, B. (2010). The role of meat consumption in the denial of moral status and mind to meat animals. Appetite, 55(1), 156-159.

https://doi.org/10.1016/j.appet.2010.05.043 
Luce, M. F., Bettman, J. R., \& Payne, J. W. (1997). Choice Processing in Emotionally Difficult Decisions. Journal of Experimental Psychology: Learning, Memory, and Cognition, 23(2), 384405.

Mathur, M. B., Peacock, J., Reichling, D. B., Nadler, J., Bain, P. A., Gardner, C. D., \& Robinson, T. N. (2021). Interventions to reduce meat consumption by appealing to animal welfare: Metaanalysis and evidence-based recommendations. Appetite, 164, 105277. https://doi.org/10.1016/j.appet.2021.105277

McGregor, I., Newby-Clark, I. R., \& Zanna, M. P. (2019). Dissonance now: How accessible discrepancies moderate distress and diverse defenses. In E. Harmon-Jones (Ed.), Cognitive dissonance: Reexamining a pivotal theory in psychology (2nd ed.). (pp. 117-138). American Psychological Association. https://doi.org/10.1037/0000135-006

Minson, J. A., \& Monin, B. (2012). Do-Gooder Derogation: Disparaging Morally Motivated Minorities to Defuse Anticipated Reproach. Social Psychological and Personality Science, 3(2), 200-207. https://doi.org/10.1177/1948550611415695

Moberly, N. J., \& Dickson, J. M. (2018). Goal conflict, ambivalence and psychological distress: Concurrent and longitudinal relationships. Personality and Individual Differences, 129, 3842. https://doi.org/10.1016/j.paid.2018.03.008

Murphy, J. J., Allen, P. G., Stevens, T. H., \& Weatherhead, D. (2005). A Meta-Analysis of Hypothetical Bias in Stated Preference Valuation. Environmental and Resource Economics, 30, 313-325.

Newby-Clark, I. R., McGregor, I., \& Zanna, M. P. (2002). Thinking and caring about cognitive inconsistency: When and for whom does attitudinal ambivalence feel uncomfortable? Journal of Personality \& Social Psychology, 82(2), 157-166. https://doi.org/10.1037//00223514.82.2.157

Nohlen, H. U., van Harreveld, F., \& Cunningham, W. A. (2019). Social evaluations under conflict: Negative judgments of conflicting information are easier than positive judgments. Social Cognitive and Affective Neuroscience, nsz045. https://doi.org/10.1093/scan/nsz045 
Nordgren, L. F., van Harreveld, F., \& van der Pligt, J. (2006). Ambivalence, discomfort, and motivated information processing. Journal of Experimental Social Psychology, 42(2), 252-258. https://doi.org/10.1016/j.jesp.2005.04.004

Norris, C. J., Do, E., Close, E., \& Deswert, S. (2019). Ambivalence toward healthy and unhealthy food and moderation by individual differences in restrained eating. Appetite, 140, 309-317. https://doi.org/10.1016/j.appet.2019.05.033

OECD, \& FAO. (2020). OECD-FAO Agriculture Outlook (Edition 2020). https://data.oecd.org/agroutput/meat-consumption.htm

Onwezen, M. C., \& van der Weele, C. N. (2016). When indifference is ambivalence: Strategic ignorance about meat consumption. Food Quality and Preference, 52, 96-105. https://doi.org/10.1016/j.foodqual.2016.04.001

Oppenheimer, D. M., Meyvis, T., \& Davidenko, N. (2009). Instructional manipulation checks: Detecting satisficing to increase statistical power. Journal of Experimental Social Psychology, 45(4), 867-872. https://doi.org/10.1016/j.jesp.2009.03.009

Ostrom, T. M. (1969). The relationship between the affective, behavioral, and cognitive components of attitude. Journal of Experimental Social Psychology, 5(1), 12-30.

Pauer, S., \& Čavojová, V. (in preparation). Cognitive bias about meat eating: Assessment, determinants, and consequences.

Permut, S., Fisher, M., \& Oppenheimer, D. M. (2019). TaskMaster: A Tool for Determining When Subjects Are on Task. Advances in Methods and Practices in Psychological Science, 2(2), 188196. https://doi.org/10.1177/2515245919838479

Perugini, M., \& Bagozzi, R. P. (2001). The role of desires and anticipated emotions in goal-directed behaviours: Broadening and deepening the theory of planned behaviour. British Journal of Social Psychology, 40(1), 79-98. https://doi.org/10.1348/014466601164704

Petty, R. E., \& Cacioppo, J. T. (1986). The elaboration likelihood model of persuasion. In Communication and persuasion (pp. 1-24). Springer. 
Piazza, J., Hodson, G., \& Oakley, A. (2020). Butchers' and deli workers' psychological adaptation to meat. Emotion. https://doi.org/10.1037/emo0000738

Piazza, J., Ruby, M. B., Loughnan, S., Luong, M., Kulik, J., Watkins, H. M., \& Seigerman, M. (2015). Rationalizing meat consumption. The 4Ns. Appetite, 91, 114-128. https://doi.org/10.1016/j.appet.2015.04.011

Priester, J. R., \& Petty, R. E. (1996). The gradual threshold model of ambivalence: Relating the positive and negative bases of attitudes to subjective ambivalence. Journal of Personality and Social Psychology, 71(3), 431.

Priester, J. R., \& Petty, R. E. (2001). Extending the bases of subjective attitudinal ambivalence: Interpersonal and intrapersonal antecedents of evaluative tension. Journal of Personality and Social Psychology, 80(1), 19-34. https://doi.org/10.1037/0022-3514.80.1.19

Proulx, T., Inzlicht, M., \& Harmon-Jones, E. (2012). Understanding all inconsistency compensation as a palliative response to violated expectations. Trends in Cognitive Sciences, 16(5), 285-291. https://doi.org/10.1016/j.tics.2012.04.002

Rees, J. H., Bamberg, S., Jäger, A., Victor, L., Bergmeyer, M., \& Friese, M. (2018). Breaking the Habit: On the Highly Habitualized Nature of Meat Consumption and Implementation Intentions as One Effective Way of Reducing It. Basic and Applied Social Psychology, 1-12. https://doi.org/10.1080/01973533.2018.1449111

Rhodes, R. E., \& Dickau, L. (2012). Experimental evidence for the intention-behavior relationship in the physical activity domain: A meta-analysis. Health Psychology, 31(6), 724-727. https://doi.org/10.1037/a0027290

Rohrer, J. M. (2018). Thinking Clearly About Correlations and Causation: Graphical Causal Models for Observational Data. Advances in Methods and Practices in Psychological Science, 16.

Rothgerber, H. (2013). Real men don't eat (vegetable) quiche: Masculinity and the justification of meat consumption. Psychology of Men \& Masculinity, 14(4), 363-375. https://doi.org/10.1037/a0030379 
Rothgerber, H. (2018). "But I Don't Eat that Much Meat": Situational Underreporting of Meat Consumption by Women. Society \& Animals. https://doi.org/10.1163/15685306-12341468

Rothgerber, H., \& Rosenfeld, D. L. (2021). Meat-related cognitive dissonance: The social psychology of eating animals. Social and Personality Psychology Compass, spc3.12592. https://doi.org/10.1111/spc3.12592

Rothman, N. B., Pratt, M. G., Rees, L., \& Vogus, T. J. (2017). Understanding the Dual Nature of Ambivalence: Why and When Ambivalence Leads to Good and Bad Outcomes. Academy of Management Annals, 11(1), 33-72. https://doi.org/10.5465/annals.2014.0066

Rozin, P. (2007). Food and eating. In S. Kitayama \& D. Cohen (Eds.), Handbook of cultural psychology (pp. 391-416). Guilford Press.

Rozin, P., \& Ruby, M. B. (2020). The moral march to meatless meals: The scripted Hebrew meat prohibitions versus the unscripted path to becoming vegetarian or vegan. In G. Hodson \& K. Dhont (Eds.), Why we love and exploit animals: Bridging insights from academia and advocacy (pp. 284-302). Routledge.

Ruby, M. B. (2012). Vegetarianism. A blossoming field of study. Appetite, 58(1), 141-150. https://doi.org/10.1016/j.appet.2011.09.019

Ruby, M. B., Alvarenga, M. S., Rozin, P., Kirby, T. A., Richer, E., \& Rutsztein, G. (2016). Attitudes toward beef and vegetarians in Argentina, Brazil, France, and the USA. Appetite, 96, 546554. https://doi.org/10.1016/j.appet.2015.10.018

Ruby, M. B., \& Heine, S. J. (2011). Meat, morals, and masculinity. Appetite, 56(2), 447-450. https://doi.org/10.1016/j.appet.2011.01.018

Schneider, I. K., Novin, S., Harreveld, F., \& Genschow, O. (2021). Benefits of being ambivalent: The relationship between trait ambivalence and attribution biases. British Journal of Social Psychology, bjso.12417. https://doi.org/10.1111/bjso.12417 
Schneider, I. K., van Harreveld, F., Rotteveel, M., Topolinski, S., van der Pligt, J., Schwarz, N., \& Koole, S. L. (2015). The path of ambivalence: Tracing the pull of opposing evaluations using mouse trajectories. Frontiers in Psychology, 6, 1-12. https://doi.org/10.3389/fpsyg.2015.00996

Schwarz, N. (1999). Self-reports-How the questions shape the answers. American Psychologist, 54(2), 93-105.

Siegrist, M., Visschers, V. H. M., \& Hartmann, C. (2015). Factors influencing changes in sustainability perception of various food behaviors: Results of a longitudinal study. Food Quality and Preference, 46, 33-39. https://doi.org/10.1016/j.foodqual.2015.07.006

Sparks, P., Conner, M., James, R., Shepherd, R., \& Povey, R. (2001). Ambivalence about healthrelated behaviours: An exploration in the domain of food choice. British Journal of Health Psychology, 6(1), 53-68. https://doi.org/10.1348/135910701169052

Stone, J., Wiegand, A. W., Cooper, J., \& Aronson, E. (1997). When Exemplification Fails: Hypocrisy and the Motive for Self-Integrity. Journal of Personality \& Social Psychology, 72(1), 54-65.

Thompson, M. M., Zanna, M. P., \& Griffin, D. W. (1995). Let's not be indifferent about (attitudinal) ambivalence. Attitude Strength: Antecedents and Consequences, 4, 361-386.

Tian, Q., Hilton, D., \& Becker, M. (2016). Confronting the meat paradox in different cultural contexts: Reactions among Chinese and French participants. Appetite, 96, 187-194. https://doi.org/10.1016/j.appet.2015.09.009

Toribio-Flórez, D., van Harreveld, F., \& Schneider, I. K. (2020). Ambivalence and Interpersonal Liking: The Expression of Ambivalence as Social Validation of Attitudinal Conflict. Frontiers in Psychology, 11, 525301. https://doi.org/10.3389/fpsyg.2020.525301

Tversky, A., \& Shafir, E. (1992). Choice under Conflict: The Dynamics of Deferred Decision. Psychological Science, 3(6), 358-361. https://doi.org/10.1111/j.1467-9280.1992.tb00047.x

Ullrich, J., Schermelleh-Engel, K., \& Böttcher, B. (2008). The moderator effect that wasn't there: Statistical problems in ambivalence research. Journal of Personality and Social Psychology, 95(4), 774-794. https://doi.org/10.1037/a0012709 
van der Weele, C. N. (2013). Meat and the benefits of ambivalence. In H. Röcklinsberg \& P. Sandin (Eds.), The ethics of consumption (pp. 290-295). Wageningen Academic Publishers. https://doi.org/10.3920/978-90-8686-784-4_47

van Harreveld, F., Nohlen, H. U., \& Schneider, I. K. (2015). The ABC of Ambivalence. Affective, Behavioral, and Cognitive Consequences of Attitudinal Conflict. Advances in Experimental Social Psychology, 52, 285-324. https://doi.org/10.1016/bs.aesp.2015.01.002

van Harreveld, F., Rutjens, B. T., Rotteveel, M., Nordgren, L. F., \& Van Der Pligt, J. (2009).

Ambivalence and decisional conflict as a cause of psychological discomfort: Feeling tense before jumping off the fence. Journal of Experimental Social Psychology, 45(1), 167-173. van Harreveld, F., Rutjens, B. T., Schneider, I. K., Nohlen, H. U., \& Keskinis, K. (2014). In doubt and disorderly: Ambivalence promotes compensatory perceptions of order. Journal of Experimental Psychology: General, 143(4), 1666-1676. https://doi.org/10.1037/a0036099 van Harreveld, F., van der Pligt, J., \& de Liver, Y. N. (2009). The Agony of Ambivalence and Ways to Resolve It: Introducing the MAID Model. Personality and Social Psychology Review, 13(1), 45-61. https://doi.org/10.1177/1088868308324518

Willett, W. (2012). Nutritional epidemiology (3rd edition). Oxford university press.

Willett, W., Rockström, J., Loken, B., Springmann, M., Lang, T., Vermeulen, S., Garnett, T., Tilman, D., DeClerck, F., Wood, A., Jonell, M., Clark, M., Gordon, L. J., Fanzo, J., Hawkes, C., Zurayk, R., Rivera, J. A., De Vries, W., Majele Sibanda, L., ... Murray, C. J. L. (2019). Food in the Anthropocene: The EAT-Lancet Commission on healthy diets from sustainable food systems. The Lancet, 393, 447-492. https://doi.org/10.1016/S0140-6736(18)31788-4

Wynes, S., \& Nicholas, K. A. (2017). The climate mitigation gap: Education and government recommendations miss the most effective individual actions. Environmental Research Letters, 12(7). https://doi.org/10.1088/1748-9326/aa7541

Zizzo, D. J. (2010). Experimenter demand effects in economic experiments. Experimental Economics, 13(1), 75-98. https://doi.org/10.1007/s10683-009-9230-z 